\title{
Pendugaan Potensi Tegakan Ekaliptus (Eucalyptus Pellita F. Meull) Menggunakan Metode Tree Sampling Dan Circular Plot
}

\author{
Muhammad Ikhwan, Emy Sadjati dan Enny Insusanty \\ Dosen Fakultas Kehutanan, Universitas Lancang Kuning, Pekanbaru \\ Jalan Yos Sudarso KM. 08 Rumbai, Pekanbaru \\ Email:mmighwan@yahoo.com,emy_mnhunilak@gmail.com, annovisa@yahoo.com
}

\begin{abstract}
S
The forest inventory is basically a data collection activities. This activity is relatively important, because the effect on further activities. Hence the data collected must have a high enough accuracy. A way of determining the sampling unit is considered to be simpler, easier, and faster is the tree sampling method.

The purpose of this study was to quantify the potential large stands of eucalyptus in the Forest of eucalyptus plants in the Faculty of Forestry and calculate the relative efficiency of sample unit.

The total area is 0.11 ha of eucalyptus stands. Unit examples used are circular, 4trees sampling, sampling 5-trees, and 6-trees sampling is done by simple random sampling method.

Potential stands of eucalyptus with method 6 sample trees have an average volume stands perplot is $0.07 \mathrm{~m}^{3}$, with the volume of the stand for the entire area is $84.71 \mathrm{~m}^{3}$ with a sampling error of $36,96 \%$. Potential stands of eucalyptus trees by the method of example 8 trees have a volume average stocking each plot is $0.04 \mathrm{~m}^{3}$, with the volume of the stand for the entire area is $43.22 \mathrm{~m}^{3}$ with a sampling error of $51.47 \%$. Potential stands of eucalyptus by using 10 sample trees have an average volume stands each plot was $0.03 \mathrm{~m}^{3}$, with the volume of the stand for the entire area is $39.74 \mathrm{~m}^{3}$ with a sampling error of $53.34 \%$. Potential stands of eucalyptus with a diameter circular sample plots of $12 \mathrm{~m}$ has an average volume stands each plot is $7.88 \mathrm{~m}^{3}$, with the volume of the stand for the entire area is $76.72 \mathrm{~m}^{3}$ with a sampling error of $14.43 \%$.
\end{abstract}

Keywords: inventory, stand, Ekaliptus

\section{PENDAHULUAN}

Informasi tentang hutan diperoleh dari data potensi hutan yang bersifat kuantitatif dan kualitatif akan dibutuhkan untuk mendukung informasi yang diperlukan. Pengambilan data potensi hutan, khususnya data yang bersifat kuantitatif dilakukan melalui kegiatan inventarisasi hutan.Kegiatan inventarisasi hutan meliputi dua teknik yakni sensus dan sampling.Teknik sensus dilaksanakan dengan me-lakukan pengukuran pada seluruh populasi (areal hutan), sementara teknik sampling dilakukan dengan 
melakukan pengukuran pada sebagian wilayah dan dianggap me-wakili seluruh areal hutan.Namun, kegiatan inventarisasi hutan lebih banyak dilakukan dengan teknik sampling mengingat keterbatasan sumberdaya manusia, biaya, dan waktu serta luas kawasan yang luas.

Inventarisasi hutan pada dasarnya merupakan kegiatan pengambilan data.Kegiatan ini tergolong penting, sebab berpengaruh terhadap kegiatan-kegiatan selanjutnya.Oleh Karena itu data yang dikumpulkan harus mempunyai keakuratan cukup tinggi, sehingga kegiatan selanjutnya yang dimaksud dapat dilakukan secara mantap. Untuk itu diperlukan metode pengumpulan data yang dianggap baik

Dalam kaitannya dengan kegiatan pengumpulan data hutan, telah dikembangkan beberapa metode baik teknik pengambilan data maupun pengolahan datanya.Metode-metode tersebut digunakan untuk menduga potensi tegakan yang ada, karena tidak mungkin dilakukan sensus terhadap tegakan hutan yang sangat luas.Dengan demikian perlu adanya perbaikanperbaikan dan penemuan metode baru yang tepat bagi kegiatan inventarisasi hutan, guna menduga potensi tegakan agar lebih praktik dan ekonomis serta mempunyai ketelitian yang tinggi.

Suatu cara penentuan unit sampling yang dianggap lebih sederhana, mudah, dan cepat adalah tree sampling methode (metode pohon contoh). Pengembangan metode tersebut untuk kegiatan inventarisasi di lapangan sedang dilakukan dan perlu terus diadakan penelitian lebih lanjut, sehingga dapat digunakan sebagai alternative yang lebih baik

Tujuan dari penelitian ini adalah untuk menghitung besar potensi tegakan Ekaliptus di Hutan Tanaman Ekaliptus di Kampus Fakultas Kehutanan berdasarkan beberapa metode sampling. Selain itu akan membandingkan metode sampling yang digunakan dalam penelitian sehingga diketahui unit contoh yang paling efisien sebagai perbandingan unit contoh yang tepat dalam penerapannya di kawasan hutan tanaman rakyat.

\section{METODE}

Penelitian ini dilaksanakan di Hutan Tanaman Ekaliptus yang terletak di Universitas Lancang Kuning. Penelitian ini 
akan dilaksanakan selama 4 bulan yaitu pada Oktober 2016 - Januari 2016

Bahan penelitian yang akan digunakan adalah tegakan hutan tanaman Ekaliptus tahun tanam 2007. Alat yang akan digunakan dalam penelitian ini adalah phi band, meteran, christien meter, kompas, stopwatch, alat tulis, tally sheet dan clinometers.

Bahan yang digunakan pada pelatihan ini adalah peta tutupan lahan kawasan Universitas Lancang Kuning, GPS, serasah yang terdapat di hutan Arboretum dan hutan Ekaliptus..

Luas areal tegakan hutan tanaman Ekaliptus pada penelitian ini adalah 0,116 ha. Pengambilan unit contohnya dilakukan dengan menggunakan unit contoh, berbentuk lingkaran, 6 trees sampling, 8 trees sampling, dan 10 trees sampling. Pengambilan petak contoh berukuran lingkaran dengan diameter 12 $\mathrm{m}$ juga dilakukan, sebagai pembanding terhadap teknik yang biasa dilakukan selama ini. Pengambilan contoh pada semua bentuk unit contoh ini dilakukan dengan metode Simple Random Sampling
Rumus yang digunakan dalam menghitung luasan petak contoh 6 trees sampling yaitu :

$$
\begin{gathered}
L i=\eta R^{2} \\
R=D_{6}+1 / 2 d_{6}
\end{gathered}
$$

Li : Luas petak ukur ke I (ha)

R : Jari-jari petak coba (petak ukur) dalam meter

D6 : Jarak dari titik pusat pengukuran sampai pohon keenam

d6 : Diameter pohon ke enam

$\eta \quad$ : Konstanta sebesar 3.141593 (22/7)

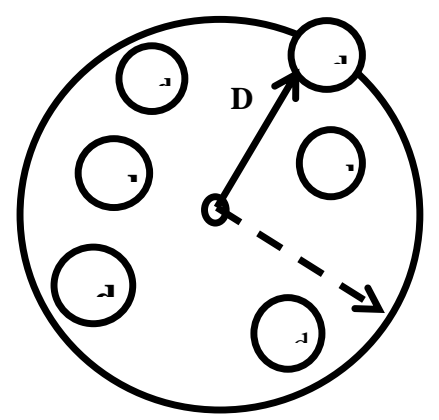

Gambar 1. Prinsip Pengukuran 6 trees Sampling

Intensitas sampling yang digunakan adalah $10 \%$, sehingga jumlah petak ukur (PU) yaitu :

$$
\mathrm{n}=\mathrm{IS} \times \mathrm{N}
$$

Jumlah unit populasi menggunakan rumus :

$$
N=\frac{A}{B}
$$

Dimana :

$\mathrm{N}$ adalah jumlah unit populasi

a adalah jumlah unit contoh yang diukur IS adalah intensitas sampling 
A adalah luas areal yang diamati (ha)

$B$ adalah luas petak ukur yang digunakan

\section{Pengolahan dan Analisis Data}

Data hasil pengukuran di lapangan akan diolah untuk memperoleh nilai dugaan volume per hektar. Rumus-rumus yang digunakan untuk mengukur potensi tegakan Ekaliptus adalah :

\section{a. Unit contoh lingkaran}

Pendugaan volume :

$$
V_{j i k} \frac{\sum_{i=1}^{k} V_{i j k}}{L_{i k}}
$$

Untuk menduga volume tegakan rata-rata per ha menggunakan rumus :

$$
\bar{V}_{i k} \frac{\sum_{i=1}^{n} V_{i j k}}{n}
$$

\section{Dimana :}

$\mathrm{V}_{\mathrm{jk}}$ : Volume tegakan per ha berdasarkan petak ukur lingkaran ke-j

$V_{\text {ikk }} \quad$ : Volume pohon ke-i dari petak ukur lingkaran ke-j

L : Luas petak ukur (0.05 ha)

$\mathrm{K}$ : Jumlah pohon dalam petak ukur lingkaran ke-j

$\mathrm{V}_{\mathrm{Ik}} \quad$ : Volume rata-rata per ha

$\mathrm{n} \quad$ : Banyak petak ukur yang diukur

\section{b. Unit contoh tree sampling}

Bentuk unit contoh tree sampling yang tidak beraturan (unequal size), sehingga setiap pendugaan yang digunakan menggunakan nilai karakteristik ratarata untuk setiap hektarnya.

\section{1) Pendugaan volume}

Volume tegakan per hektar pada setiap petak ukur dapat menggunakan rumus :

$$
\mathrm{V}_{\mathrm{jt}} \frac{\sum_{\mathrm{i}=1}^{\mathrm{k}=1}\left(\mathrm{~V}_{\mathrm{i}-1}\right)+\frac{1}{2} V_{k}}{\mathrm{~L}_{\mathrm{jt}}}
$$

Rata-rata volume tegakan per hektar diduga dengan rumus :

$$
\overline{\mathrm{V}}_{\mathrm{t}} \frac{\sum_{\mathrm{j}=1}^{\mathrm{n}}\left(\mathrm{V}_{\mathrm{jt}} x L_{j t}\right)}{\sum_{j=1}^{n} L_{j t}}
$$

Dimana :

$\mathrm{V}_{\mathrm{jt}}:$ Volume tegakan per ha petak ukur ke-j

$V_{i}$ : Volume pohon ke-i

$\mathrm{L}_{\mathrm{jt}}$ : Luas unit contoh ke-j (ha)

$k$ : Jumlah pohon contoh

$V_{t}$ : Volume rata-rata per ha untuk seluruh tegakan

$n$ : Jumlah unit contoh $(j=1,2,3, .$. n) 
2) Penduga nilai tengah/ratarata $(\bar{y})$

$$
\begin{aligned}
\overline{\mathrm{y}} & \frac{\sum_{\mathrm{i}=1}^{\mathrm{n}} \mathrm{y}_{i}}{n} \\
\mathrm{Y}_{\mathrm{i}}: & \begin{array}{l}
\text { Nilai karakteristik yang } \\
\text { diukur padaunit contoh } \\
\text { ke-i }
\end{array} \\
\mathrm{n}: & \text { Jumlah unit contoh }
\end{aligned}
$$

3) Ragam dugaan rata-rata contoh $\left(S y^{2}\right)$

$$
\begin{gathered}
S_{\bar{y}}^{2}=\frac{S_{y}^{2}}{n} \\
S_{\bar{y}}=\sqrt{S_{\bar{y}}^{2}} \\
S_{y}^{2}=\frac{\sum_{\mathrm{i}=1}^{\mathrm{n}} \mathrm{y}_{i}^{2}-\left(\left(\sum_{\mathrm{i}=1}^{\mathrm{n}} y_{i}\right)^{2} / n\right)}{n-1} \\
\mathrm{~S}_{\mathrm{y}}: \text { simpangan baku populasi }
\end{gathered}
$$

\section{4) Selang kepercayaan total populasi}

Rumus untuk menghitung selang kepercayaan total populasi adalah

$$
\widehat{\boldsymbol{Y}}=\mathbf{N} . \widehat{\boldsymbol{y}}
$$

Selang kepercayaan total populasi :

$$
\hat{Y} \pm\left(\frac{t_{\frac{\alpha}{n}-1} .}{S_{\hat{y}}}\right)
$$

$\mathrm{N}$ : Jumlah unit populasi

Selang kepercayaan rata-rata

populasi :

$$
\hat{y} \pm\left(\frac{t_{n}-1}{n} S_{\hat{y}}\right)
$$

5) Kesalahan penarikan contoh / sampling error (SE)

$$
\begin{gathered}
\hat{y} \pm\left(\frac{t_{\frac{\alpha}{n}}-1 .}{\hat{y}}\right) \\
S E=\frac{\left(\frac{t_{\alpha}-1 .}{n} S_{\hat{y}}\right)}{\hat{y}} \times 100 \%
\end{gathered}
$$

$\mathrm{t}_{(\alpha / 2)}$ : nilai dari tabel titik kritis distribusi T

Tingkat kepercayaan yang digunakan adalah 95\%, sehingga $\alpha=100 \%-95 \%=0.05$

\section{6) Efisiensi Relatif (ER)}

Ukuran efisiensi suatu metode dibandingkan dengan metode lainnya dapat dilihat dari nilai efisiensi relatif (relative efficiency). Efisiensi relatif pada penelitian ini membandingkan metode tree sampling dengan metode plot sampling. Rumus efisiensi relatif menurut Sutarahardja (1999) adalah:

$$
E R_{b-a}=\frac{S E_{a}^{2} .}{S E_{b}^{2} .}
$$

Dimana :

$$
\begin{array}{cl}
\mathrm{ER}_{\mathrm{b}-\mathrm{a}} & : \text { Efisiensi metode } \mathrm{b} \\
& \text { terhadap metode a } \\
S E_{a}^{2}: & : \begin{array}{l}
\text { Kesalahan sampling } \\
\text { metode a }
\end{array} \\
S E_{b}^{2}: & : \begin{array}{l}
\text { Kesalahan sampling } \\
\text { metode b }
\end{array}
\end{array}
$$


Ketentuan :

Bila $E R>1$, maka metode tree sampling lebih efisien dibandingkan metode plot sampling

Bila $E R<1$, maka metode tree sampling tidak efisien dibandingkan metode plot sampling

Bila $\mathrm{ER}=1$, maka kedua metode memiliki tingkat efisien yang relatif sama

\section{HASIL DAN PEMBAHASAN}

Tegakan ekaliptus yang menjadi lokasi penelitian dan berlokasi di Universitas Lancang Kuning memiliki luas 0,116 ha, jarak tanam $2 \mathrm{~m} \times 2 \mathrm{~m}$, dengan jumlah pohon sebanyak 176 pohon, diameter terkecil adalah $7,3 \mathrm{~cm}$, diameter terbesar adalah $35,3 \mathrm{~cm}$, tinggi pohon terendah adalah $5 \mathrm{~m}$, pohon tertinggi adalah 29,3 m, volume pohon terkecil adalah $0,03 \mathrm{~m}^{3}$ dan volume pohon terbesar adalah $1,23 \mathrm{~m}^{3}$.

Bentuk plot ukur untuk unit contoh 6-trees sampling adalah berbentuk lingkaran dengan diameter beragam. Adanya keragaman diameter ini disebabkan oleh posisi terjauh dari pohon pusat tidak sama disebabkan oleh tidak adanya pohon. Sehingga luas plot menjadi berbeda. Jumlah total plot yang dapat dibuat adalah 46 plot, dan yang menjadi plot contoh sebanyak 10 plot, sehingga intensitas sampling adalah $21,68 \%$.

Volume rata-rata tegakan perplot adalah $0,07 \mathrm{~m}^{3}$. Luas area penelitian adalah $1160 \mathrm{~m}^{2}$, maka volume tegakan untuk seluruh area adalah $84,71 \mathrm{~m}^{3}$ dengan sampling error sebesar 36,96\%.

Volume rata-rata tegakan perplot untuk 8-trees sampling adalah $0.04 \mathrm{~m}^{3}$. Luas area penelitian adalah $1160 \mathrm{~m}^{2}$, maka volume tegakan untuk seluruh area adalah $43,22 \mathrm{~m}^{3}$ dengan sampling error sebesar $51,47 \%$.

Volume rata-rata tegakan perplot untuk 10-trees sampling adalah $0,03 \mathrm{~m}^{3}$. Luas area penelitian adalah $1160 \mathrm{~m}^{2}$, maka volume tegakan untuk seluruh area adalah $39,74 \mathrm{~m}^{3}$ dengan sampling error sebesar $53,34 \%$.

Volume rata-rata tegakan perplot untuk plot berbentuk lingkaran adalah $7,88 \mathrm{~m}^{3}$. Luas area penelitian adalah $1.160 \mathrm{~m}^{2}$, maka volume tegakan untuk seluruh area adalah 76,72 $\mathrm{m}^{3}$ dengan sampling error sebesar $14,43 \%$.

Pada penelitian ini, efisiensi relatif pada penelitian ini membandingkan metode tree sampling dengan metode plot 
sampling yang berbentuk lingkaran. Perbandingan nilai efisiensi relatif antara metode tree sampling dengan plot sampling yang berbentuk lingkaran disajikan pada Tabel 1.

Tabel 1. Nilai Efisiensi Relatif (er) Untuk Setiap Unit Contoh

\begin{tabular}{|c|l|c|}
\hline No. & $\begin{array}{c}\text { Perbandingan Unit } \\
\text { Contoh }\end{array}$ & $\begin{array}{c}\text { Nilai } \\
\text { Efisiensi } \\
\text { Relatif }\end{array}$ \\
\hline 1 & $\begin{array}{l}6 \text { pohon berbanding } \\
8 \text { pohon }\end{array}$ & 1,39 \\
\hline 2 & $\begin{array}{l}6 \text { pohon berbanding } \\
10 \text { pohon }\end{array}$ & 1.44 \\
\hline 3 & $\begin{array}{l}8 \text { pohon berbanding } \\
10 \text { pohon } \\
6 \text { pohon berbanding } \\
\text { circular plot }\end{array}$ & 1.04 \\
\hline 4 & 0,39 \\
\hline
\end{tabular}

Sumber : hasil pengolahan (2017)

Tabel 1 memperlihatkan bahwa teknik tree sampling dengan 6 unit pohon lebih efisien dari pada teknik tree sampling dengan 8 dan 10 pohon dengan nilai efisiensi relatif berturut-turut adalah 1,39 dan 1,44. Teknik tree sampling dengan 8 unit pohon lebih efisien daripada teknik tree sampling dengan 10 unit pohon. Tapi nilai efisiensi relatif antara teknik tree sampling 6 unit pohon dengan teknik sampling circular plot adalah 0,39 ini menunjukkan bahwa teknik tree sampling 6 unit pohon tidak lebih efisien dari metode teknik circular plot. Nilai efisiensi relatif sangat dipengaruhi oleh nilai sampling error dari teknik sampling. Jika sampling error suatu teknik sampling lebih kecil maka nilai efisiensi relatifnya akan lebih besar.

\section{KESIMPULAN}

Kesimpulan dari penilitian ini adalah :

1. Teknik tree sampling dengan 6 unit contoh mampu menduga lebih baik potensi atau volume tegakan Eukaliptus dibandingkan dengan teknik sampling yang lain.

2. Teknik sampling circular plot memiliki nilai ketelitian dan efisiensi relatif yang lebih baik dibandingkan dengan teknik sampling yang lain.

\section{SARAN}

Sampling error untuk semua metode teknik sampling memiliki nilai lebih dari $10 \%$ sehingga dapat dianggap bahwa hasil penelitian dengan metode tersebut dapat dianggap kurang teliti. Hal ini disebabkan oleh tidak semua pohon Eukaliptus tumbuh di kawasan penelitian sehingga pada beberapa lokasi tidak terdapat pohon Eukaliptusnya. Oleh 
karena itu disarankan penelitian ini dilakukan ditempat yang lebih mewakili

\section{DAFTAR PUSTAKA}

Cochran, W.G. 1991. Teknik Penarikan Sample (di-Indonesia-kan oleh Rudiansyah dan R.Osman). UIPress. Jakarta.

Husch, B. $1987 . \quad$ Perencanaan Inventarisasi Hutan (diIndonesiakan-oleh Agus Setyarso. UI-Press. Jakarata.

Rusyadi, 1982. Studi Bermacam Petak Coba dalam Pendugaan Potensi Tegakan Jati di KPH Bojonegoro Perum Perhutani Unit II Jawa Timur.Jurusan Manajemen Hutan Fakultas Kehutanan Institut Pertanian Bogor. Bogor. (tidak diterbitkan)

Simon, H. 1987. Manual Inventore Hutan. UI-Press. Jakarta

Sutarahardja, S,S. Hardjoprajitno, S. Manan, Ngadino, W. Soekotjo, P. Wiroatmodjo, Y. Setiadi, R. Atmawidjaja, H. B. Nasoetion, dan J. Soediono, 1982. Pedoman dan Pentunjuk Inventarisasi Hutan.Direktorat Bina Program Kehutanan. Bogor.

Sutarahardja, S.1997. Metode Petak Berubah (Tree Sampling) dalam Pendugaan Volume Tegakan Hutan Tanaman. Laboratorium Inventarisasi Hutan, Fakultas Kehutanan IPB. Bogor
Sutarahardja S. 1999. Metode Sampling dalam Inventarisasi Hutan. Bogor (ID): Laboratorium Inventarisasi Hutan, Fakultas Kehutanan IPB 